\title{
樹木の存在する河道の流況特性
}

\section{Flow Characteristics in Channel with Vegetation}

\author{
渡邊康玄 ${ }^{1} \cdot$ 北條絋次 $^{2} \cdot$ 清水康行 $^{3}$ \\ By Yasuharu WATANABE, Kouji HOUJYOU and Yasuyuki SHIMIZU
}

\begin{abstract}
It is very important in river management works to take into account the influences of the vegetation to the flow during the flood. Logarithmic or parabolic law can be a good assumption for the vertical profile of downstream. velocity distribution in open channel flow without vegetation. However, these assumptions cannot be applied to the flow through the vegetation because of the strong effect of the resistance caused by trees.

In this paper, the vertical distribution of flow through the vegetation is predicted theoretically. The bed drag coefficient has to be changed in order to calculate the depth averaged downstream velocity accurately.
\end{abstract}

Keywords: flow velocity, vegetation, resistance coefficient,

1.はじめに

近年、河川に対して水辺環境としてのうるおいやゆとり、あるいは水との触れ合い等を望む声が高まっ ている。これまでの河川事業においてす周辺環境への配慮はなされていたが、より積極的な配慮が望ま れている。この社会の要請に応える一つの方法として河川の高水敷に植栽あるいはすでに生えている樹 木を残した河川計画を立案する方向に動きつつある。しかし、河道内に樹木が存在する場合、河積の減 少や樹木による粗度の增加に伴う河道内の流下能力の低減、洪水時における流木の発生等、治水への悪 影響が考えられる。流下能力の低減に関しては樹木群が流れにどのような影響を与えるかを、また流木 に関しては樹木に働く流水力を把握する必要がある。このように河川環境（植生）を配虑した河道計画 立案のためには、樹木が存在する場の流況を把握することが必要不可欠である。

本研究は、樹木群内部の流況を把握し、流れにおよぼす樹木群の影響を検討するために用いる、樹木 群を含む流況計算手法を提案することを目的とする。

\section{2. 樹木群内流速の水深方向分布}

\section{$2 \cdot 1$ 基礎式}

樹木の抗力を考慮した等流の運動方程式は、（1）式で表される。

$$
0=-\tilde{g} \frac{\partial \widetilde{H}}{\partial \widetilde{x}}+\frac{\partial}{\partial \tilde{z}}\left(\tilde{\epsilon} \frac{\partial \widetilde{u}}{\partial \widetilde{z}}\right)-\frac{\tilde{a}}{2} C_{d} \widetilde{u}^{2}
$$

\footnotetext{
${ }^{1}$ 正会員 工修 開発土木研究所主任研究員 水工部河川研究室

（062 札幌市豊平区平岸 $1-3$ )

${ }^{2}$ 正会員 北海道開発庁水政課長

(100 東京都千代田区霞が関 $3-1-1$ )

${ }^{3}$ 正会員 工博 開発土木研究所副室長 水工部河川研究室

( 062 札幌市豊平区平岸 $1-3$ )
} 
ここで、 $\tilde{g}$; 重力加速度, $\widetilde{H} ;$ 水位, $\tilde{\epsilon}$; 渦動粘性係数 $\left(=\kappa / 6 \widetilde{u_{*}} \tilde{h}\right), \tilde{h}$; 水深, $\widetilde{u_{*}}$; 摩擦速度 $(=\sqrt{\tilde{g} \tilde{h} i}), \tilde{u}$; $\tilde{x}$ 軸方向流速, $\tilde{a}$; 樹木密度 $(=\tilde{d} /(\tilde{s} \tilde{l})), \tilde{d}$; 樹木の直径, $\tilde{s}$; 樹木の横断方向間隔, $\tilde{l}$; 樹木の縦断方向間隔, $C_{d} ;$ 樹木の抗力係数， $\kappa$; カルマン定数である。なお、 の付いた変数は、有次元を示している。

水面で剪断力が無く、河床で剪断力が河床摩擦と釣り合うことから、(2)、(3) 式が成り立っ。

$$
\frac{\partial \tilde{u}}{\partial \tilde{z}}=0 ; \tilde{z}=\tilde{h} \quad(2), \tilde{\epsilon} \frac{\partial \widetilde{u}}{\partial \tilde{z}}=C_{b} \widetilde{u}_{b}^{2} ; \tilde{z}=0
$$

ここで、 $C_{b} ;$ 河床の抵抗係数， $\widetilde{u_{b}} ;$ 河床における流速である。

(1)、(2)、（3）式は、 $u=\tilde{u} / \widetilde{u_{*}}, a=\tilde{a} \tilde{h}, z=\tilde{z} / \tilde{h}$ を用いて無次元化を行うと、(4)、(5)、(6) 式 となる。

$$
1+\frac{\kappa}{6} \frac{\partial^{2} u}{\partial z^{2}}-\frac{a}{2} C_{d} u^{2}=0 \quad \text { (4) }, \frac{\partial u}{\partial z}=0 ; z=1 \quad \text { (5) }, \frac{\partial u}{\partial z}=\frac{6}{\kappa} C_{b} u^{2} ; z=0
$$

$2 \cdot 2$ 摄動法による近似解 ${ }^{1), 2), 3)}$

（4）式を、（5)、（6）式の境界条件のるとで摃動法を用いて解くこととする。

$$
\phi=\sqrt{\frac{a}{2} C_{d}} u, \nu=\frac{\kappa}{6} \sqrt{\frac{2}{a C_{d}}}, \quad p=\nu^{-1 / 2} z
$$

と置くと、（4）式は、

$$
1+\frac{d^{2} \phi}{d p^{2}}-\phi^{2}=0
$$

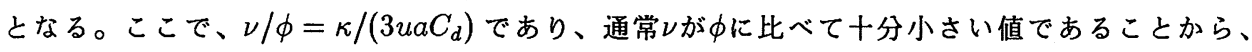

$$
\phi=\phi_{0}+\nu \phi_{1}+\nu^{2} \phi_{2}+\cdots
$$

と仮定し、（7）式に代入すると、

$$
1+\left(\frac{d^{2} \phi_{0}}{d p^{2}}+\nu \frac{d^{2} \phi_{1}}{d p^{2}}+\nu^{2} \frac{d^{2} \phi_{2}}{d p^{2}}+\cdots\right)=\phi_{0}^{2}+2 \nu \phi_{0} \phi_{1}+\cdots
$$

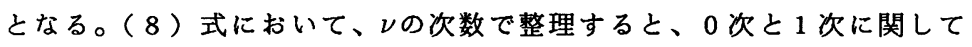

$$
1+\frac{d^{2} \phi_{0}}{d p^{2}}=\phi_{0}^{2} \quad(9), \frac{d^{2} \phi_{1}}{d p^{2}}=2 \phi_{0} \phi_{1}
$$

が得られる。（9）式の解の 1 つは、

$$
\phi_{0}=1
$$

であり、これを（１１０）式に代入すると、一般解として

$$
\phi_{1}=C_{0} \exp (\sqrt{2} p)+C_{1} \exp (-\sqrt{2} p)
$$

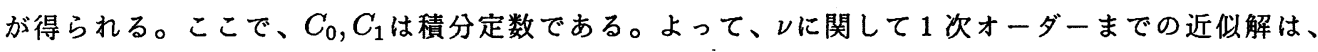

$$
\phi=1+\nu\left[C_{0} \exp (\sqrt{2} p)+C_{1} \exp (-\sqrt{2} p)\right]
$$

となり、結局 $u$ は、

$$
u=\sqrt{\frac{2}{a C_{d}}}+\frac{\kappa}{3 a C_{d}}\left[C_{0} \exp (\chi z)+C_{1}(-\chi z)\right]
$$

で表される。ここで、 


$$
\chi=\left(\frac{72 a C_{d}}{\kappa^{2}}\right)^{\frac{1}{4}}
$$

境界条件 (5) 式 (6) 式を用いて、積分定数 $C_{0}, C_{1}$ は

$$
C_{0}=\frac{-\beta+\sqrt{\beta^{2}-4 \alpha \gamma}}{2 \alpha}, C_{1}=C_{0} \exp (2 \chi)
$$

となる。ここで、

表 -1 実験の諸元

\begin{tabular}{|c|c|c|c|c|}
\hline & $\begin{array}{c}\text { 流量 } \\
\mathrm{l} / \mathrm{s}\end{array}$ & $\begin{array}{c}\text { 水深 } \\
\mathrm{cm}\end{array}$ & 勾配 & 河床抵抗係数 \\
\hline case 2 & 3.54 & 5.5 & $1 / 472$ & 0.008 \\
\hline case 3 & 3.50 & 4.9 & $1 / 317$ & 0.028 \\
\hline case 5 & 4.04 & 3.8 & $1 / 314$ & 0.028 \\
\hline
\end{tabular}

$$
\begin{gathered}
\alpha=\frac{2 \kappa}{3 a^{2} C_{d}^{2}} C_{b}[1+2 \exp (2 \chi)+\exp (4 \chi)] \\
\beta=\left(\frac{32 C_{b}}{a^{3} C_{d}^{3}}\right)^{\frac{1}{2}}[1+\exp (2 \chi)]-\left(\frac{8 \kappa^{2}}{9 a^{3} C_{d}^{3}}\right)^{\frac{1}{4}}[1-\exp (2 \chi)] \\
\gamma=\frac{12 C_{b}}{\kappa a C_{d}}
\end{gathered}
$$

\section{$2 \cdot 3$ 近似解の適合性}

攝動法で求めた流速の水深方向分布の適合性をみるために、川 幅 $0.4 m$ 、流路長 $5.0 m$ のアクリル直線水路を用いて、縦断方 向流速の水深方向分布の測定を行った。実験は、樹木の配置パ ターンとして、直径 $6.0 \mathrm{~mm}$ のアクリル棒を流路全体に縦横断方 向 $0.08 m$ の間隔で千鳥に配置したすの 2 ケース ( case 2, case 3 ) と、川幅方向半断面に配置したすの 1 ケース ( case5) について 行った。また、流路の河床はアクリル板としているが、case 3 と case5 はアクリル板に粒径 $1.8 \mathrm{~mm}$ の砂を添付したものを河床と した実験である。流速の測定には、樹木以外の影響をなくすた め、非水没型のレーザー流速計を用いた。実験の水理量を表一 1 に示す。

case 2 と case 3 について、実験から得られた流速と（１１）式 から得られる流速を比較したものが、図一 1、2である。流速お よび河床からの高さは、それぞれ摩擦速度および水深で無次元 化している。また、解析解が樹木群内の平均的な流速としている ことから、実験值は、縦横断方向間隔 $2 \mathrm{~cm}$ のメッシュで測定し たすのを平均した值を用いた。解析解は、河床付近で実験值よ りあ若干小さく水面付近で若干大きな值となる傾向がうかがえ るが、その程度は小さく十分実験値を再現しているすのと思わ れる。また、図には比較のため樹木が存在しない場合の流速分 布（放物分布）を示した。さらに、樹木を水路片側のみに設置

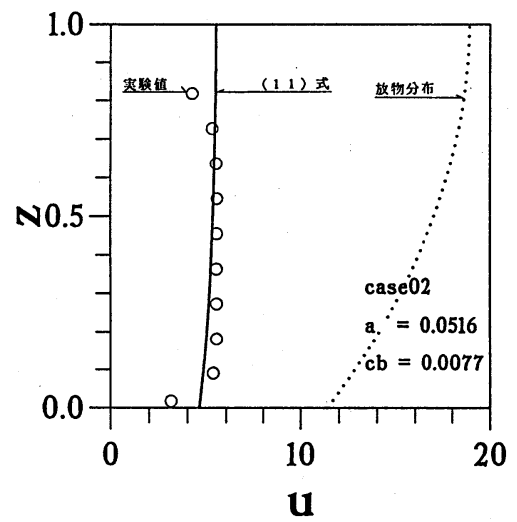

図-1 水深方向の流速分布 ( case 2 )

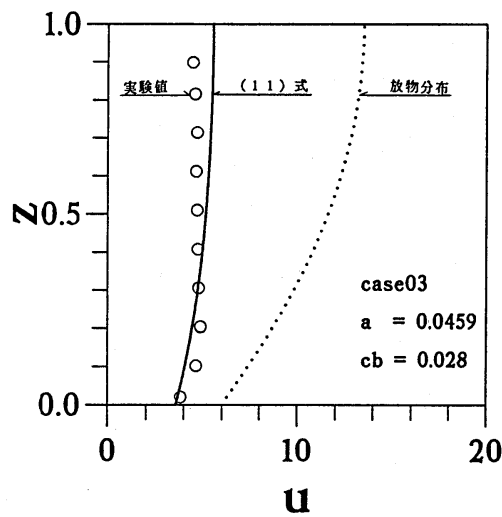

図 -2 水深方向の流速分布 ( case 3 ) し、流速分布が図ー3のように測定された case5 において、樹木群内と樹木の影響が無 い箇所およびその中間での流速分布について 解析解と比較したのすを図ー4に示した。樹 木の影響が及ばない範囲では放物分布で十分 表現できるが、樹木の影響が及ぶに従って、流 速分布は、放物分布から離れ水深方向に一様化 していることが明確に示されている。このよう に、樹木群内の流速分布は放物分布で表現でき ないことから、樹木群内の流速分布を把握する には、本解析解を用いる必要がある。

一方、樹木群外で樹木の影響を受ける範囲の 流速分布は、放物分布および本解析解による分

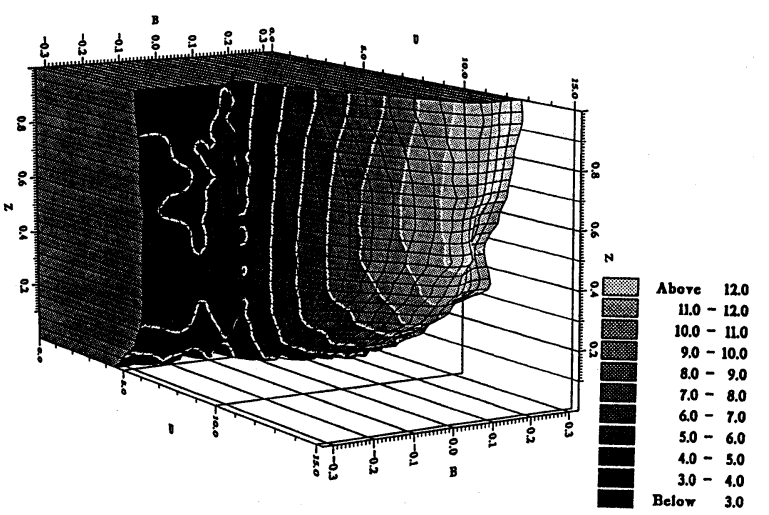

図一 3 流速分布コンター（case5） 
布の中間的分布になっているすのの、中央部分が出っ張る分布形 を示しており両分布形とは明らかに異なっている。平面流況を 扱ううえでは、この部分の流速分布も重要であり、樹木群が影響 を及ぼす範囲む含めて今後検討を進めていく必要がある。

\section{3. 水深方向平均流速の算定}

\section{$3 \cdot 1$ 樹木群による影響}

樹木群を含む河道の平面流況計算において水深方向平均流速 を用いる場合、前節で確認したように樹木群内と樹木群外では 水深方向の流速分布が異なることから、この影響を取り込む必 要がある。樹木の抗力を考慮した等流の運動方程式である（4） 式を境界条件（5）、（6）式のあとで水深方向に積分すると

$$
0=1-C_{b} u_{b}^{2}-\frac{a}{2} C_{d} \int_{0}^{1} u^{2} d z
$$

となる。これを、水深方向平均流速 $\langle u\rangle$ で表現すると

$$
0=1-C_{f}^{\prime}\langle u\rangle^{2}-\frac{a^{\prime}}{2} C_{d}\langle u\rangle^{2}
$$

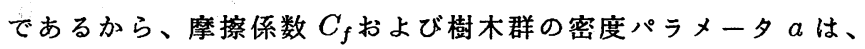
$C_{f}^{\prime} 、 a^{\prime}$ と変化し、

$$
C_{f}^{\prime}=C_{b} \frac{u_{b}^{2}}{\langle u\rangle^{2}} \quad, \quad a^{\prime}=\frac{a \int_{0}^{1} u^{2} d z}{\langle u\rangle^{2}}
$$

となる。また、( $\left.\begin{array}{ll}1 & 1\end{array}\right)$ 式より、

$$
\begin{aligned}
\langle u\rangle & =\sqrt{\frac{2}{a C_{d}}}-\frac{\kappa}{3 a C_{d} \chi} C_{0}[1-\exp (2 \chi)] \\
u_{b} & =\sqrt{\frac{2}{a C_{d}}}+\frac{\kappa}{3 a C_{d}} C_{0}[1+\exp (2 \chi)]
\end{aligned}
$$

であるから、

$$
C_{f}^{\prime}=C_{b} \frac{\left\{\sqrt{\frac{2}{a C_{d}}}+\frac{\kappa}{3 a C_{d}} C_{0}[1+\exp (2 \chi)]\right\}^{2}}{\left\{\sqrt{\frac{2}{a C_{d}}}-\frac{\kappa}{3 a C_{d} \chi} C_{0}[1-\exp (2 \chi)]\right\}^{2}}
$$

となる。( $\left.\begin{array}{ll}1 & 2\end{array}\right)$ 式より、樹木が存在する場合の流れに対する全 抵抗は、 $\left(C_{f}^{\prime}+a^{\prime} C_{d} / 2\right)$ であり、この值が $C_{b}, a$ にってどのよ うに変化するかを示したすのが図ー 5 である。なお本検討におい ては、 $C_{d}$ の值として円柱の抗力係数である 1.2 を用いている。 $a$ および $C_{b}$ の増加ととあに全抵抗は大きくなるが、 $C_{b}$ の増加に対 してょりあaの増加に対する増加の方がより顕著となっている。 この図を用いることで、河床の抵抗係数と樹木の密度パラメー 夕を与えると概略の平均流速を知ることができる。また、全抵 抗を $C_{f}^{\prime}$ と $a^{\prime} C_{d} / 2$ とに分離して示したすのが図一6、7である。 $a^{\prime} C_{d} / 2$ は、 $C_{b}$ によってほとんど変化せずほぼ $a$ のみによって規 定されている。一方、 $C_{f}^{\prime}$ は、 $C_{b}$ の増加とともに大きくなる傾向 があり、その割合は $a$ の值が大きい程大きくなる。さらに、全抵 抗に対して、 $C_{f}^{\prime}$ と $a^{\prime} C_{d} / 2$ のどちらがより大きなウエイトを占め ているかを把握するため、 $C_{f}^{\prime} /\left(C_{f}^{\prime}+a^{\prime} C_{d} / 2\right)$ の值を図ー 8 に

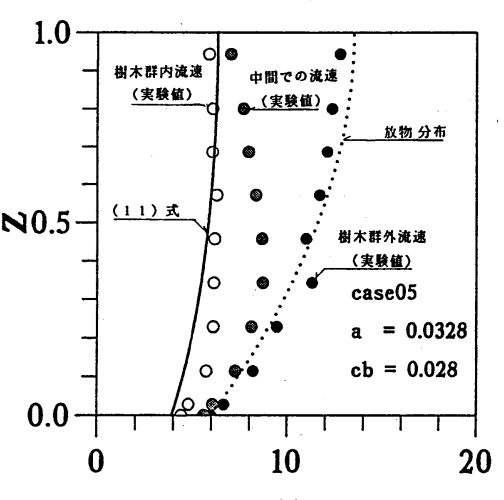

$\mathbf{u}$

図-4 水深方向の流速分布 ( case5)

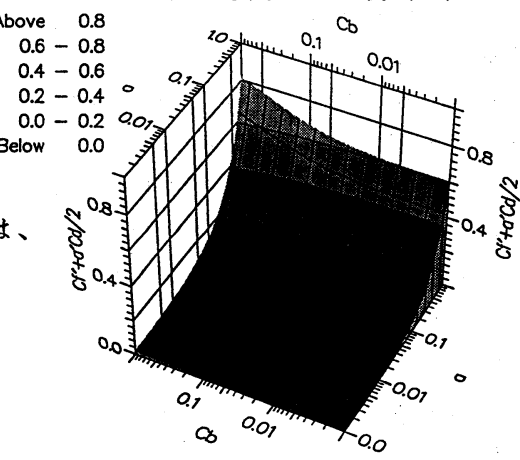

$$
\text { 図- } 5 \quad C_{f}^{\prime}+a^{\prime} C_{d} / 2 \text { の変化 }
$$

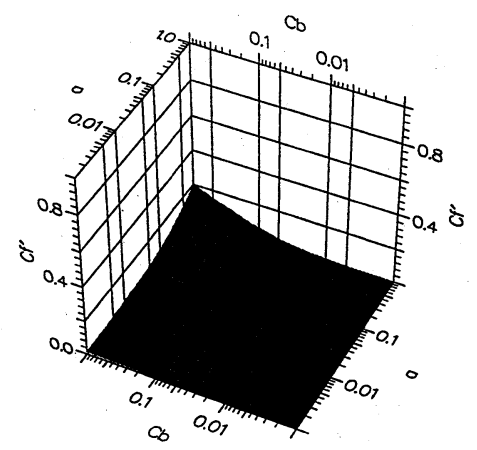

図-6 $C_{f}^{\prime}$ の変化

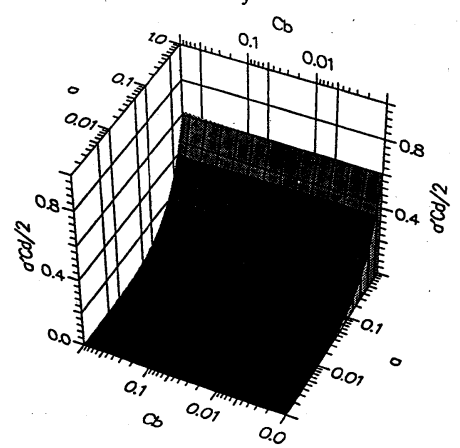

図-7 $\quad a^{\prime} C_{d} / 2$ の変化 
示した。 $C_{b}$ が大きく $a$ が小さい範囲では $C_{f}^{\prime}$ が、 $a$ が大きく $C_{f}$ が 小さい範囲では $a^{\prime} C_{d} / 2$ が卓越していることが確認できる。

次に、 $a^{\prime}$ は、 $C_{b}, a$ によってほとんど変化しないことが判明し たが、C $C_{f}^{\prime}$ が樹木群の存在しない場合に比較してどの程度変化す るかを把握することとする。樹木がない場合の水深方向流速分 布は、（4）式の左辺第 3 項を省略したものを用いると、

$$
u_{0}=-\frac{3}{\kappa} z^{2}+\frac{6}{\kappa} z+\frac{1}{\sqrt{C_{b}}}
$$

で表され、これより水深方向平均流速 $\left\langle u_{0}\right\rangle$ および底面流速 $u_{0 b}$ は

$$
\left\langle u_{0}\right\rangle=\frac{2}{\kappa}+\frac{1}{\sqrt{C_{b}}}, \quad u_{0 b}=\frac{1}{\sqrt{C_{b}}}
$$

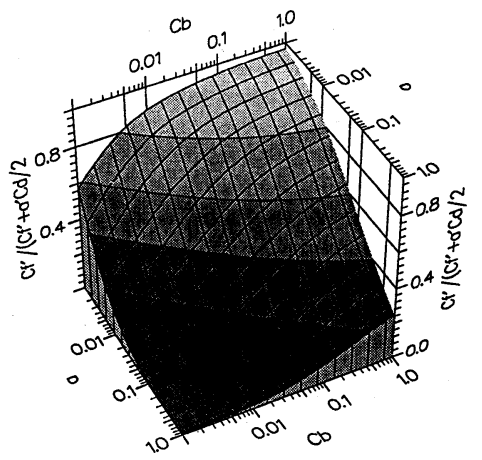

となり、樹木群が存在しない場合の摩擦係数 $C_{f 0}$

図-8 $C_{f}^{\prime} /\left(C_{f}^{\prime}+a^{\prime} C_{d} / 2\right)$ の変化 は、

$$
C_{f 0}=\frac{1}{\left(\frac{2}{\kappa}+\frac{1}{\sqrt{C_{b}}}\right)^{2}}
$$

となる。よって、樹木の存在による流速分布の 変化に伴う摩擦係数の変化は、

$$
\frac{C_{f}^{\prime}}{C_{f 0}}=C_{b}\left(\frac{2}{\kappa}+\frac{1}{\sqrt{C_{b}}}\right)^{2}
$$

となる。



図-9 $\widetilde{n_{m}^{\prime}} / \widetilde{n_{m 0}}$ の変化

河川計画では、通常河床の抵抗等をマニングの粗度係数 $\widetilde{n_{m}}$ で表現していることから、( $\left.\begin{array}{ll}1 & 3\end{array}\right)$ 式の関 係をマニングの粗度係数で表現することとする。いま、摩擦係数をマニングの粗度係数で表現すると

$$
C_{f}=\frac{g \widetilde{n_{m}^{2}}}{\tilde{h}^{\frac{1}{3}}}
$$

であることより、樹木群の存在する場合の粗度係数の变化量は、

$$
\frac{\widetilde{n_{m}^{\prime}}}{\widetilde{n_{m 0}}}=\left(\frac{2}{\kappa} \sqrt{C_{b}}+1\right) \frac{\left\{\sqrt{\frac{2}{a C_{d}}}+\frac{\kappa}{3 a C_{d}} C_{0}[1+\exp (2 \chi)]\right\}}{\left\{\sqrt{\frac{2}{a C_{d}}}-\frac{\kappa}{3 a C_{d} \chi} C_{0}[1-\exp (2 \chi)]\right\}}
$$

となる。四一9は、横軸に $a$ 、縦軸に $\widetilde{n_{m}^{\prime}} / \widetilde{n_{m 0}}$ をとったすのである。樹木密度の増加とともに変化量す 増加する倾向を示し、その增加の割合は、摩擦係数が大きいほど大きくなる。このように、水深方向に 平均した流速を計算する場合、樹木群の影響を取り込むためには、樹木の抗力以外に流速分布の変化に 伴う粗度係数の変化を考慮する必要がある。

$3 \cdot 2$ 直線河道における横断方向の流速分布

前節までの結果を利用し、直線河道におけるる横断方向の流速分布がどのようになるかを見ることと する。

運動方程式を、樹木群外および樹木群内についてそれぞれ

$$
0=1-C_{f 0}\left\langle u_{0}\right\rangle^{2}+\xi \frac{\partial^{2}\left\langle u_{0}\right\rangle}{\partial y^{2}} \quad(14), 0=1-\left(C_{f}^{\prime}+\frac{1}{2} a^{\prime} C_{d}\right)\langle u\rangle^{2}+\xi \frac{\partial^{2}\langle u\rangle}{\partial y^{2}}
$$

とする。ここで、乡は横断方向の渦動粘性係数 $\tilde{\epsilon_{y}}$ の大きさを表す係数であり、

$$
\tilde{\epsilon_{y}}=\xi \widetilde{u_{*}} \tilde{h}
$$

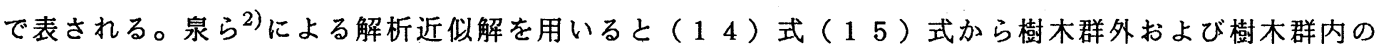
流速分布はそれぞれ、 


$$
\left\langle u_{0}\right\rangle=\frac{1}{\sqrt{C_{f 0}}}\left[1+C_{2} \exp \left(-\sqrt{\frac{2}{\zeta}} y\right)\right],\langle u\rangle=\frac{1}{\sqrt{C_{f}^{\prime}+\frac{a^{\prime}}{2} C_{d}}}\left[1+C_{3} \exp \left(\sqrt{\frac{2}{\eta}} y\right)\right]
$$

となる。ここで、

$$
\begin{gathered}
C_{2}=\frac{\eta-\zeta}{\zeta+(\eta \zeta)^{0.5}}, \quad C_{3}=-\left(\frac{\zeta}{\eta}\right)^{0.5} C_{2} \\
\zeta=\xi \frac{1}{C_{f 0}}, \eta=\xi \frac{1}{\sqrt{C_{f}^{\prime}+\frac{a^{\prime}}{2} C_{d}}}
\end{gathered}
$$

である。case 5 の水深方向に平均した横断方向の流速分 布は、図ー10のように計算される。なお比較のため、 摩擦係数 $C_{f}^{\prime}$ 之樹木密度を表す係数 $a^{\prime}$ が变化しなかった 場合についても示している。摩擦係数および樹木密度を 表す係数を変化させた場合の方が流速分布をより正確に 再現している。しかし、その違いはそれほど大きなるの とはなっていない。case 5 は、 $C_{b}=0.028, a=0.0328$ であり、図ー 9 から $\widetilde{n_{m}^{\prime}} / \widetilde{n_{m 0}}$ の值が 1.3 程度と低く、ま た図ー8 から河床による抵抗の全抵抗に占める割合が 約 4 割である。このことから、摩摖係数および樹木密 度を表す係数を変化させた場合とさせなかった場合の 違いがより明確にならなかった理由と思われる。

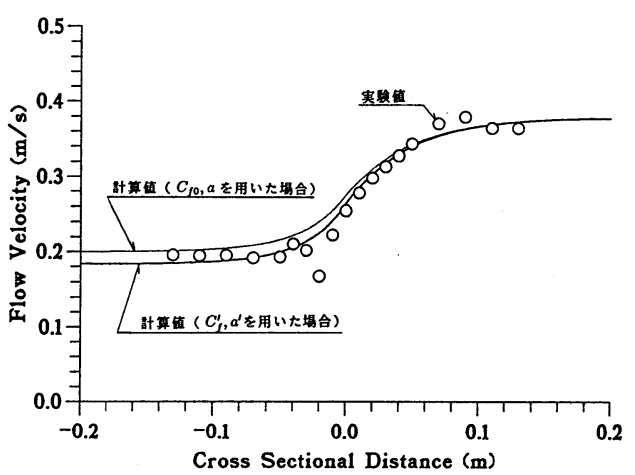

図-1 0 水深方向平均流速の横断方向分布

しかし、一般に河川において樹木が問題となる䇢所は、河床抵抗の大きな高水敷であり、河床の抵抗 係数 $C_{b}$ の值が大きな箇所である。いま、粗度係数 $=0.05$ 、水深 $=1 m$ とすると、 $C_{b}=0.5$ となる。この 場合 $\widetilde{n_{m}^{\prime}} / \widetilde{n_{m 0}}$ はかなり大きな值となり、この影響を無視し得なくなる。

\section{4.おわりに}

環境に配慮した河道計画が望まれるようになり、河道に樹木が存在する場合の流況計算法が種々提案 されている。しかしこれらは、樹木の存在による水深方向の流速分布の変化を見込んでおらず、必ずし あ正確に樹木が存在する流れを再現しているとはいいきれなかった。特に、河道において樹木が問題と なる箇所は高水敷であり、一般に水深方向の流速分布の変化に伴う粗度係数の変化が大きなるのと予想 される。この場合水深方向の流速分布の変化を見込まなければ、河道の流下能力上危険側の算出を行う こととなる。

本研究では、樹木群内の等流状態における水深方向の流速分布を解析的に求め、水深方向に平均した 流速を算出する場合の粗度係数の変化量を算出した。これを用いることにより、より正確に流速が算出 できる。また、2 次元浅水流モデルに粗度係数の変化を組み込むことにより、樹木が存在する河道の平 面流況等も計算可能と考元られる。

しかしながら、樹木群内と樹木群外の影響が相互に干涉する場所における水深方向の流速分布は不明 であり、今後検討を進める必要がある。

\section{参考文献}

1. 寺沢寛一; 自然科学者のための数学概論応用編、岩波書店、1969 年 7 月

2. 泉典洋、池田駿介、伊藤力生; 流水抵抗及び浮遊砂濃度に及ぼす植生の効果、第 33 回水理講演会 論文集、1989 年 2 月

3. 山崎真一、石川忠晴、金丸督司; 開水路平面せん断流に関する実験的研究、第 39 回年次学術講演 会講演概要集、1984 年 10 月 